\title{
Clientelismo personalizado en Colombia: una aproximación histórico-institucional a un estudio de caso
}

\author{
Clientelismo personalizado na Colômbia: uma abordagem \\ histórico-institucional para um estudo de caso
}

\section{Personalized clientelism in Colombia: a historical- institutional approach to a case study}

\author{
(iD) Luis A. González Tule \\ Universidad del Norte, Barranquilla, Colombia \\ Itule@uninorte.edu.co \\ iD Carlos Enrique Guzmán Mendoza \\ Universidad del Atlántico, Barranquilla, Colombia \\ ceguzman@mail.uniatlantico.edu.co \\ (iD) Ángel Tuirán Sarmiento \\ Universidad del Norte, Barranquilla, Colombia \\ angelt@uninorte.edu.co
}

Resumen: Gran parte de la literatura politológica considera que el clientelismo es dañino para las democracias. En menor medida, otras aproximaciones estiman que el clientelismo es un mecanismo de atención de demandas para poblaciones vulnerables. Este artículo pretende contribuir al conocimiento generado en torno a este tema a través de un estudio de caso. Se busca: 1) mostrar cómo opera el clientelismo, tomando como referencia el municipio de Barranquilla, Colombia; 2) proponer explicaciones para entender la lógica clientelar; y 3 ) indagar en sus efectos sobre el régimen democrático. A partir de un enfoque histórico-institucional, argumentamos que el clientelismo en Barranquilla es de naturaleza personalizada y no partidista como resultado de los arreglos políticos y los cambios institucionales que han 
tenido lugar en Colombia desde mediados del siglo XX. Con base en la evidencia podemos afirmar que la política clientelar ha permitido a las élites económico-políticas locales perpetuarse en el poder y que las asimetrías entre gobernantes y gobernados persistan.

Palabras clave: Clientelismo político. Instituciones informales. Intercambio desigual. Barranquilla. Colombia.

Resumo: Grande parte da literatura politológica considera o clientelismo prejudicial às democracias. Em menor escala, outras abordagens estimam que o clientelismo seja um mecanismo para atender às demandas de populações vulneráveis. Este artigo tem por objetivo contribuir com o conhecimento sobre esse tema por meio de um estudo de caso. Buscase: 1) mostrar como o clientelismo funciona, tomando como referência o município de Barranquilla, na Colômbia; 2) propor explicações para entender a lógica clientelar; e 3) investigar seus efeitos no regime democrático. Com base em uma abordagem histórico-institucional, argumentamos que o clientelismo em Barranquilla é personalista e não partidário diante dos arranjos políticos e das mudanças institucionais que ocorreram na Colômbia desde meados do século XX. A partir de evidências, pode-se afirmar que a política clientelista permitiu que as elites econômico-políticas locais se perpetuassem no poder e que as assimetrias entre governantes e governados persistissem.

Palavras-chave: Clientelismo político. Instituições informais. Troca desigual. Barranquilla. Colômbia.

Abstract: Much of the political science literature regards clientelism as harmful to democracies. To a lesser extent, other approaches estimate that clientelism is a mechanism that meets the needs of vulnerable populations. This article aims to contribute to knowledge built on this theme through a case study. It seeks to: 1 ) show how clientelism works, taking the municipality of Barranquilla, Colombia, as a reference; 2) propose explanations to grasp the clientelist rationale; and 3) investigate its effects on the democratic regime. From a historical-institutional perspective, we argue that clientelism in Barranquilla has a personalistic 
rather than a partisan nature, as a result of political arrangements and institutional changes that have taken place in Colombia since the mid-20 century. Evidence allows us to claim that clientelist politics has allowed the local economic-political elites to perpetuate in power and that the asymmetries between rulers and ruled persist.

Keywords: Political clientelism. Informal institutions. Unequal exchange. Barranquilla. Colombia.

Data de recebimento: 13/02/2019

Data de aprovação: 06/04/2020 
Clientelismo personalizado en Colombia: una aproximación histórico-institucional... Luis A. González Tule • Carlos Enrique Guzmán Mendoza • Ángel Tuirán Sarmiento

\section{Introducción}

En la costa Caribe de Colombia', las relaciones clientelares son un "hecho notorio" desde hace más de dos décadas (DÍAZ, 1986). El municipio de Barranquilla, la ciudad más importante de esta región ${ }^{2}$, no es ajena a esa dinámica, tal y como se han encargado de documentar distintos medios de comunicación locales ynacionales. Sin embargo, a pesar de la cobertura mediática encargada de denunciar públicamente las prácticas informales e ilegales y de los continuos informes que alertan sobre riesgos que presenta el libre ejercicio del voto en el municipio y en el departamento ${ }^{3}$, existe un déficit en el desarrollo de investigaciones que aborden el fenómeno teniendo a Barranquilla como unidad de análisis ${ }^{4}$ a diferencia de la atención que han recibido otras entidades de la misma región ${ }^{5}$.

Siguiendo el razonamiento de Leal y Dávila (2010), acerca de la importancia que adquirieron los municipios como esferas edificadoras del sistema político, este artículo busca contribuir al desarrollo de nuevo conocimiento en torno a las relaciones informales a nivel local en Colombia. Tomando como caso de estudio el municipio de Barranquilla, se describe la estructura y el funcionamiento de una red clientelar y se indaga en los factores que han favorecido esa forma política de intercambio personalizado. Esto último desde una perspectiva histórico-institucional. La investigación se apoya en entrevistas realizadas a informantes clave siguiendo el método muestra redireccionada (respondent-driven sampling [RDS]).

\footnotetext{
1 La costa Caribe está conformada por 7 departamentos: a) Atlántico; b) Bolívar; c) Cesar; d) Córdoba; e) La Guajira; f) Magdalena; y g) Sucre.

2 Barranquilla es uno de los grandes centros urbanos de Colombia. La ciudad capital del departamento del Atlántico es considerada por muchos la capital de la región Caribe (FERRO y LLANOS, 2016). Para 2019, el municipio de Barranquilla registra una población de 1.236.202 habitantes y una extensión territorial de 166 km2, ubicándose como la cuarta ciudad más poblada e importante del país. Ver ubicación geográfica en Anexo 1.

3 Informes recientes de la Misión de Observación Electoral (MOE) (MOE, 2018, 2019) han advertido sobre los riesgos en materia electoral que presenta la región, en particular el departamento del Atlántico, cuya capital es Barranquilla. Para las elecciones generales de 2018 , más del $57 \%$ de los municipios de este departamento se encontraba en situación de riesgo consolidado de fraude electoral (MOE, 2018), y para las elecciones locales de 2019 el $48 \%$ estuvo en alerta por riesgo de trashumancia (MOE, 2019). El municipio de Barranquilla no escapa a la preocupación de organizaciones como la MOE, siendo clasificado como municipio de alto riesgo de fraude en elecciones locales recientes (MOE, 2019).

4 Con la excepción de las investigaciones de Tuirán y Villalba (2018) y González, Guzmán y Tuirán (2019), el clientelismo en Barranquilla no sido abordado desde la academia.

5 Sobre el estudio del clientelismo en otras entidades de la región Caribe, se destacan los estudios de Díaz (1986) y Ocampo (2014), quienes analizan el fenómeno en los departamentos de Sucre y Córdoba, respectivamente.
} 
A partir de éstas fue posible conocer cómo se conforma y funciona una red clientelar en el municipio. Se argumenta que el acuerdo formal por el que los dos partidos tradicionales pusieron fin al conflicto -Frente Nacional- y los cambios institucionales, ocurridos principalmente en la década de 1980 en Colombia, favorecieron la existencia y el mantenimiento del clientelismo personalizado en el ámbito de la política local. Esta configuración ha permitido a las élites económico-políticas locales perpetuarse en el poder y, a su vez, que las asimetrías entre gobernantes y gobernados persistan.

Para alcanzar los objetivos planteados el texto está dividido de la siguiente forma:

- La primera parte ofrece una aproximación teóricoconceptual del clientelismo en que, además de definir el término, se exponen las principales perspectivas de análisis y se puntualiza la diferencia entre clientelismo personalizado y partidario;

- La segunda parte demarca los aspectos metodológicos y las fuentes de información que dan sustento a la investigación;

- Untercer apartado describe cómo funcionayse organiza una red clientelar personalizada en Barranquilla, identificando 2 escalas de organización: a) la red ascendente; y b) la red descendente;

- Una cuarta parte ahonda en los factores que ayudan a entender cómo se fueron configurando las relaciones centro-periferia y político-elector que dieron como resultado un tipo particular de clientelismo en el caso de estudio; y

- Después de esto, se da paso a las reflexiones finales a la luz de los hallazgos.

\section{Clientelismo político: consideraciones normativas y conceptuales}

La historia del clientelismo muestra que éste ha sido abordado como una categoría analítica y una etiqueta moral (VOMMARO y 
COMBES, 2016). El concepto, por un lado, representa un fenómeno político que denota una relación personalizada, un intercambio y un modo de distribución; y por otro lado, denota una carga valorativa sobre principios e ideales asociados a un espacio, un momento y una disciplina del conocimiento. Con base en muy variados criterios y desde distintas perspectivas, la academia ha producido una ingente literatura sobre este particular, la cual abarca su impacto en la democracia (PIATTONI, 2001), su relación con el nivel de desarrollo y el sistema político (SCOTT, 1969; KITSCHELT y WILKINSON, 2007), así como la comprensión de significados y símbolos que intervienen en la relación (AUYERO, 1997).

Uno de los principales debates gira en torno a la forma en que este fenómeno impacta o se relaciona con la democracia. Desde la Ciencia Política, para la mayor parte de los estudiosos el clientelismo es perjudicial para el régimen porque, entre otros motivos, invierte la lógica de los mecanismos de rendición de cuentas (STOKES, 2005), es incompatible con la libertad de asociación (IPPOLITOO'DONNELL, 2007), y es utilizado por la élite como instrumento para mantenerse en el poder (HAGOPIAN, 1992). Académicos de otras disciplinas, como Sociología y Antropología -y en menor medida también algunos politólogos- ven el clientelismo como una forma de distribución de recursos (SHEFTER, 1994; AUYERO, 2012). Para esos autores, en contextos sociales de grandes desigualdades, donde el Estado tiene poca presencia y es incapaz de satisfacer las demandas ciudadanas, las relaciones clientelares son un medio por el cual las comunidades menos favorecidas solventan algunos de sus problemas.

La perspectiva del clientelismo -ya sea como forma corruptora o como complemento- está en estrecha relación con la valoración de la democracia -vista en términos procedimentales y sustantivos-y con la aproximación analítica desde la cual se aborda el fenómeno (GONZÁLEZ, 2019b). En el estudio del clientelismo predominan dos nociones que difieren entre sí tanto en sus razonamientos como en el método y las explicaciones sugeridas. Quienes centran su atención en la acción racional de los individuos 
Clientelismo personalizado en Colombia: una aproximación histórico-institucional... Luis A. González Tule • Carlos Enrique Guzmán Mendoza • Ángel Tuirán Sarmiento

para explicar su comportamiento sostienen que los actores que participan en el intercambio -patrones, intermediarios y clientesactúan interesadamente para alcanzar un fin específico. Las causas subyacentes que dan continuidad al clientelismo, desde esta noción, son las condiciones estructurales como el desarrollo económico y democrático, la fortaleza de las instituciones, etc. En cambio, quienes ponen énfasis en la acción normativa analizan las dimensiones subjetiva y simbólica del intercambio y sostienen que los individuos responden como norma moral a los favores recibidos, primando la idea de reciprocidad y la confianza mutua más allá de la maximización de ganancias (AUYERO, 1997). Como acción normativa, se busca entender el clientelismo a partir de códigos de conducta, lealtades y performances construidos a lo largo del tiempo.

En este artículo tomamos posición al respecto, pues desde nuestra comprensión el clientelismo entraña connotaciones perjudiciales para la salud de la democracia a nivel subnacional. En consonancia con dicha postura, el clientelismo es entendido como un intercambio personalista, particularista y desigual, de carácter permanente, entre un patrón y un cliente a través de un intermediario, en el que el patrón otorga al cliente prestaciones materiales, bienes y servicios, a cambio de apoyo político-electoral y lealtad (GONÇALVES, 1997; AUYERO, 2012; GONZÁLEZ, 2019a; BRIQUET, 2020)6.

La desigualdad en la relación patrón-cliente es un elemento central en la definición anterior, ya que el patrón posee o tiene acceso a medios tangibles e intangibles de vital importancia para el cliente (RONIGER, 1990; BRIQUET, 2020). Las malas condiciones de la clientela y el deficiente funcionamiento de las instituciones encargadas de dar atención a las demandas de la población hacen de la mediación política una necesidad. Los clientes recurren a su líder con la intención de solucionar algún problema. A cambio, el líder solicitará respaldo político y apoyo electoral. En ese intercambio

6 La relación es de carácter personalista porque une a dos personas y particularista porque lo hace a través de beneficios particulares y no universales (GONÇALVES, 1997). Otra característica fundamental del clientelismo es su permanencia a lo largo del tiempo, a diferencia de la compra de voto que se realiza en periodos electorales (HAGENE, 2015). 
Clientelismo personalizado en Colombia: una aproximación histórico-institucional... Luis A. González Tule • Carlos Enrique Guzmán Mendoza • Ángel Tuirán Sarmiento

permanente se crean símbolos y vínculos de confianza mutua que van más allá del interés de ambos actores (AUYERO, 1997). Pero también se crea dependencia de parte de los clientes, dado que la ayuda recibida soluciona una necesidad apremiante o un problema a mediano plazo, pero es insuficiente para cambiar las condiciones de la clientela en el largo plazo (GONZÁLEZ, 2019b). Esta lógica funcional a los intereses del patrón, además de violar principios del ideal democrático (PIATTONI, 2001), mantiene las desigualdades preexistentes entre los participantes del intercambio y puede ser, como en el caso de Barranquilla, un instrumento de "dominación oligárquica" por parte de la élite gobernante (HAGOPIAN, 1992, p. 249).

\section{Clientelismo personalizado y clientelismo partidario}

Las características específicas que adopta el clientelismo son resultado del desarrollo histórico y de las condiciones políticas de la sociedad en que se asienta esta práctica. Retomando la propuesta planteada por Kopecký (2015), en su estudio sobre patronazgo en Europa ${ }^{7}$, se podría marcar la primera diferencia entre un clientelismo partidario y uno personalizado. En el clientelismo partidario es la agrupación política la que opera como "patrón colectivo" en la relación de intercambio (KOPECKÝ, 2015, p. 109). En esta modalidad clientelar, el partido es "el agente fundamental en la distribución de recompensas materiales" y simbólicas a las clientelas (KOPECKÝ, 2015, p. 112). De tal manera que la lealtad y el apoyo del electorado son hacia el partido, y los mediadores son una pieza más dentro de la estructura piramidal que se moviliza siguiendo indicaciones de la organización y con recursos propios del partido.

Al otro lado del continuo de intercambios políticos informales se encuentra el clientelismo personalizado, en que el patrón está representado comúnmente en la figura del político como actor

7 Kopecký (2015) analiza el patronazgo partidario y lo define como la capacidad que tienen los partidos para asignar gente en cargos públicos. 
Clientelismo personalizado en Colombia: una aproximación histórico-institucional... Luis A. González Tule • Carlos Enrique Guzmán Mendoza • Ángel Tuirán Sarmiento

individual ${ }^{8}$. Aquí, el político, y no el partido, es el poseedor de la red clientelar y el encargado de conseguir recursos que serán distribuidos a la clientela a través de sus mediadores. Estos recursos pueden provenir de una o varias agrupaciones partidistas, según los acuerdos pactados, y el tamaño de la red en torno al patrón es inversamente proporcional a la capacidad de negociación frente a los partidos. Como es de suponer, las lealtades que derivan de este intercambio no se sustentan en la militancia partidista ni son construidas con base en afinidades programático-ideológicas, sino que las sostiene la función que cumple el patrón en la sociedad.

Tradicionalmente, el clientelismo personalizado ha estado vinculado al contexto sociopolítico. En concreto, a países con un bajo nivel de desarrollo, en proceso de democratización o de reciente consolidación de la democracia. En zonas rurales el modelo clásico también se ha hecho Ilamar clientelismo "oligárquico-tradicional" (GONÇALVES, 1997, p. 35). En el modelo oligárquico-tradicional la figura del patrón recae en caciques locales que monopolizan los recursos y el acceso a éstos. La relación con la clientela es dual -es decir, sin intermediación-, asimétrica y fuertemente personalizada. Bajo este esquema, el patrón ofrece al cliente bienes y servicios de primera necesidad para su subsistencia, nutriendo así una relación de dependencia alimentada por la desigualdad y sustentada en el poder que ostenta el patrón (GONÇALVES, 1997).

Como señala Kopecký (2015), en zonas menos desarrolladas económicamente y en áreas rurales, los vínculos clientelares y la intermediación adquieren particular relevancia. Pero ese vínculo se ve amenazado por la modernización ${ }^{9}$ y el desarrollo de los partidos de masas $^{10}$. El clientelismo partidario está más vinculado a la etapa posterior del clientelismo oligárquico-tradicional, conocida como

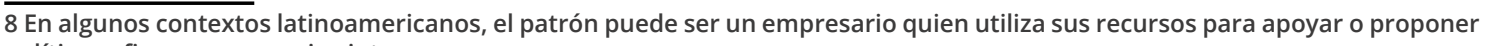
políticos afines a sus propios intereses.

9 La modernización, siguiendo con Kopecký (2015), trae consigo la profesionalización de la burocracia y, con ello, sistemas meritocráticos con reglas establecidas para promover, remover o asignar cargos públicos. Esto afectaría la asignación de cargos a través de favores o lealtades. La modernización, asimismo, puede disminuir la demanda de favores, bienes y servicios particularizados "en la medida en que las sociedades también se hacen más ricas y educadas", pues los ciudadanos "ganan capacidad para lidiar con la burocracia por sí mismos" (KOPECKÝ, 2015, p. 113).

10 Estos últimos alinean al elector en torno a un programa político o ideológico, reemplazando las formas personalistas de representación. Para algunos autores, los partidos de masas, al crear un vínculo programático, una vez que lleguen al gobierno tratarán de evitar las prácticas clientelares (SHEFTER, 1994).
} 
Clientelismo personalizado en Colombia: una aproximación histórico-institucional... Luis A. González Tule • Carlos Enrique Guzmán Mendoza • Ángel Tuirán Sarmiento

"patrocinio de mediación", en la que el apoyo político es orientado colectivamente por el partido y/o el Estado (GONÇALVES, 1997, p. 36). No obstante las diferencias marcadas por la literatura sobre el tipo de intercambio asociado al contexto en que se genera, estudios recientes enfatizan en analizar a mayor profundidad el fenómeno por la complejidad del mismo. Sólo así es posible entender que democracia y desarrollo económico, de una parte, y clientelismo, de otra, no son polos opuestos del espectro, sino que interactúan en una misma dimensión en regiones como América Latina (HILGERS, 2012). Observar la compleja realidad de las sociedades modernas también permite afirmar, como mostrará este artículo, que en el clientelismo personalizado la relación patrón-cliente no es dual, sino de intermediación a través de los brokers (mediadores), y que este fenómeno no es exclusivo de sociedades tradicionales o rurales.

Cuadro 1 - Clientelismo partidario versus clientelismo personalizado

\begin{tabular}{lll}
\hline Actores & \multicolumn{1}{c}{ Partidario } & \multicolumn{1}{c}{ Personalizado } \\
\hline Patrón & Partido político & Político; Cacique \\
\hline Mediadores & Líderes partidistas & Líderes independientes \\
\hline $\begin{array}{l}\text { Elementos del } \\
\text { intercambio }\end{array}$ & & \\
\hline Identificación-lealtad & Partidista & Con el líder y/o patrón \\
\hline Distribución de recursos & $\begin{array}{l}\text { Dentro del partido y } \\
\text { verticalmente }\end{array}$ & $\begin{array}{l}\text { Intra o interpartidista según } \\
\text { acuerdos entre patrones y partidos }\end{array}$ \\
\hline $\begin{array}{l}\text { Diseño de estrategia } \\
\text { Clientelar }\end{array}$ & $\begin{array}{l}\text { A cargo de los militantes } \\
\text { del partido }\end{array}$ & $\begin{array}{l}\text { A cargo del patrón y líderes } \\
\text { independientes }\end{array}$ \\
\hline $\begin{array}{l}\text { Factores que impactan en } \\
\text { el tipo de intercambio }\end{array}$ & Fuente: Elaborado por los autores. \\
\hline $\begin{array}{l}\text { Institucionalización del } \\
\text { sistema de partidos }\end{array}$ & $\begin{array}{l}\text { Alta: mayor identificación } \\
\text { partidista }\end{array}$ & $\begin{array}{l}\text { Baja: menor } \\
\text { identificación partidista }\end{array}$ \\
\hline & &
\end{tabular}

Teniendo en cuenta lo anterior, tanto en el clientelismo partidario como en el personalizado, la relación patrónintermediario-cliente no deja de ser personalista y particularista en los términos señalados al inicio del apartado. Asimismo, el 
intercambio de favores, bienes y servicios por apoyo políticoelectoral y lealtad está presente en ambas formas. De modo que las principales diferencias son tanto procedimentales, en términos del modo en que opera el intercambio, como teleológicas, en relación con los propósitos que sirve el partido dentro de la relación (KITSCHELT, 2000), es decir, en cómo éste se relaciona con, y se ve afectado por, el entorno. Así, además de variables estructurales como el nivel de desarrollo o el grado de democratización, las variables sistémicas juegan un papel relevante en la consecución del tipo de intercambio político informal. Por ejemplo, sin ánimo de caer en argumentos concluyentes, existen más probabilidades de que el partido sea el patrón colectivo cuando hay una mayor institucionalización del sistema, es decir, cuando hay una mayor identificación ideológica y un sólido arraigo del partido en la sociedad (MAINWARING y TORCAL, 2005). Mientras que a menor institucionalización del sistema o frente a la pérdida de identificación en las preferencias ideológicas (KOPECKÝ, 2015), mayor propensión a que la relación clientelar se personalice en patrones individuales.

En términos organizativos, las diferencias en el modo en que opera el intercambio son manifiestas. Como es bien sabido, el clientelismo puede desarrollarse en varios niveles de agregación, que son: 1) individual; 2) colectivo (sindicatos, iglesias, grupos organizados de la sociedad civil, entre otros); y 3 ) distrital (donde se concentra la base de apoyo electoral) (WARNER, 2001). En el clientelismo partidario no sólo el suministro de incentivos selectivos está a cargo del partido, sino que la estrategia de comunicación con el electorado, la atención de demandas y la distribución de dichos recursos son actividades orquestadas desde la cúpula partidista. En cambio, en el clientelismo personalizado las actividades anteriores están a cargo del patrón individual, quien trabaja directamente con los mediadores -tanto suyos como independientes- y con el electorado.

Por último, es importante señalar que la distinción entre clientelismo partidario y clientelismo personalizado atiende a 
tipos ideales, por lo que las características que adopte uno u otro en la práctica dependerán también de factores contextuales y coyunturales. De tal manera que variables como el sistema electoral, la competitividad electoral, el nivel de descentralización administrativa y política, los acuerdos políticos y la cultura ciudadana pueden propiciar que algunos de los elementos abordados se solapen mutuamente, generando modelos más bien mixtos.

\section{Datos y método}

La principal fuente de información que sirvió para dar forma al entramado clientelar en Barranquilla proviene de 20 entrevistas semi-estructuradas, realizadas a informantes clave. Las entrevistas fueron celebradas en 4 olas en distintos puntos de la ciudad. Las primeras 3 olas se cubrieron durante los siguientes periodos: 1) septiembre-diciembre de 2016; 2) febrero-abril de 2017; y 3) noviembre-diciembre de 2017. Los informantes clave fueron 5 concejales del municipio, 4 líderes sociales, 4 miembros partidistas -de diferentes agrupaciones- y 4 miembros de 2 Juntas de Acción Comunal (JAC). En una última ola, que tuvo lugar entre septiembre y noviembre de 2019, fueron entrevistados 3 excandidatos a edil -dos compitieron en las elecciones regionales de 2019 y uno en las de 2015-. La técnica empleada para llevar a cabo las entrevistas se conoce como muestra redireccionada (método RDS). Esta técnica permite trabajar con "poblaciones ocultas", cuyas características son la inexistencia de una muestra representativa y el hecho de que los miembros poseen información que no es de dominio público (HECKATHORN, 1997).

El criterio de selección de la población oculta fue la posición que los miembros ocupan en la red clientelar, de modo que se buscó tanto a mediadores (brokers) como a patrones políticos (patrons). Para aproximarse a dicha población fue necesario seguir los métodos de "informantes clave" y de "bola de nieve" de las poblaciones ocultas. Las entrevistas con los primeros informantes 
Clientelismo personalizado en Colombia: una aproximación histórico-institucional... Luis A. González Tule • Carlos Enrique Guzmán Mendoza • Ángel Tuirán Sarmiento

clave permitieron contactar a más miembros de la red, generando así un efecto bola de nieve. La "muestra redireccionada" resultó apropiada para los fines de la investigación puesto que permitió conocer, en voz de sus principales actores, algunas de las estrategias informales de captación de votos que no suelen hacerse públicas. Para proteger la privacidad de los entrevistados su identidad se mantiene en anonimato. Como fuente complementaria y de contrastación de información, se consultaron noticias y artículos de prensa relativos al clientelismo en la región Caribe.

\section{Clientelismo personalizado en Barranquilla}

Las entrevistas celebradas para este estudio permitieron identificar 2 escalas de funcionamiento de una red clientelar personalizada en Barranquilla ${ }^{11}$. La primera, nombrada descendente, está conformada por un patrón, llamado barón ${ }^{12}$, quien está al frente de una casa política13, 2 o 3 "anillos" de intermediarios (capitanes, coordinadores y líderes, según el tamaño de la red y la función de los intermediarios dentro de la misma) y el electorado. El patrón, como se verá más adelante, es una pieza clave dentro de la estructura clientelar, ya que representa la personalización de la política en el ámbito municipal. La figura del patrón por lo general recae en los congresistas, senadores y empresarios y/o contratistas del gobierno. Excepcionalmente algunos alcaldes y concejales llegan a ser patrones. En el caso de estos últimos, su peso dentro de la red es proporcional a su experiencia política, alianzas formadas, capacidad para lograr acuerdos y, principalmente, a la cantidad de votos obtenidos.

La Figura 1 muestra el esquema clientelar de la escala descendente. En dicha figura hay 2 tipos de patrón: a) el que pone

\footnotetext{
11 La idea de las dos escalas de relaciones proviene de Díaz (1986). Sin embargo, Díaz (1986) identificó la influencia del “jefe político" en un ámbito regional que frente al poder central es cliente, mientras que frente a instancias regionales es patrón. 12 El "barón electoral o político" es quien está a la cabeza de la casa política. Es la persona que posee el control sobre los recursos políticos, sociales y económicos y los intercambia con los clientes para que estos puedan tener acceso a ellos, o a bienes públicos que de otra forma sería casi imposible obtener o de difícil consecución.

13 El término "casa política" se refiere a la estructura política liderada por el barón o cacique cuya conformación y funcionalidad están basadas en reglas de localidad y parentesco, aunque puede tener un carácter ideológico y militante relacionado con un partido político (OCAMPO, 2014).
} 
Clientelismo personalizado en Colombia: una aproximación histórico-institucional... Luis A. González Tule • Carlos Enrique Guzmán Mendoza • Ángel Tuirán Sarmiento

o apoya a un candidato; y b) el patrón-candidato. El tipo de patrón importa en el sentido que fluye la red. Como se aprecia en dicha figura, un patrón está al frente de una maquinaria clientelar que fluye por debajo de él conformada por 3 anillos de mediadores, quienes, a su vez, actúan como intermediarios entre el candidato y el electorado. La personalización de la política y las necesidades de la población han promovido que la atención de demandas -desde las inmediatas hasta las más complejas- pase ineludiblemente por la intervención de mediadores políticos.

Figura 1. Red clientelar descendente en Barranquilla
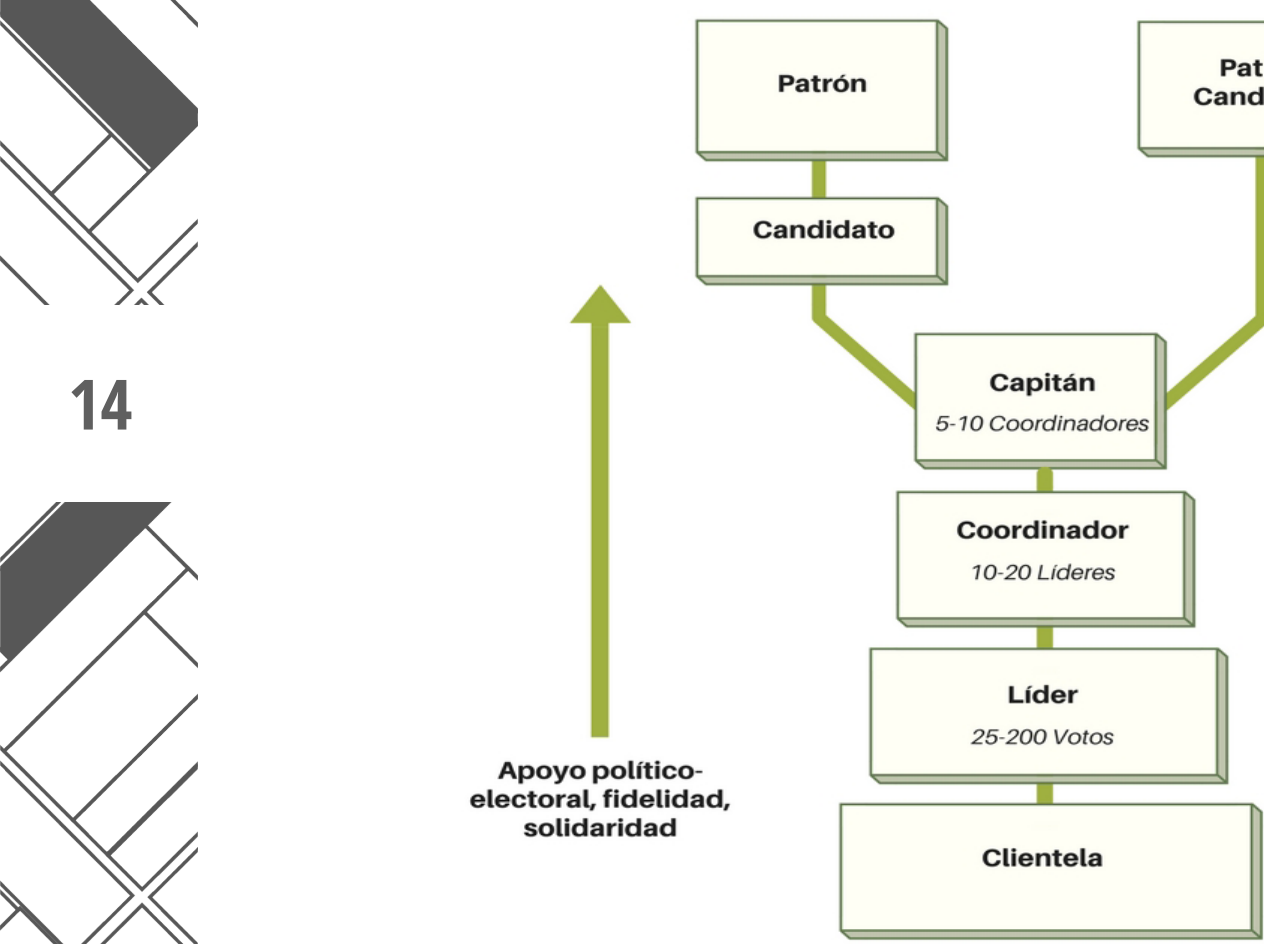

Logística,

comunicaciones,

información, bienes,

electoral,

solidaridad

Fuente: Elaborado por los autores.

El vínculo que establecen los intermediarios con el elector es construido a lo largo del tiempo y se nutre por la reciprocidad del intercambio y los lazos de lealtad tejidos. En zonas de menor penetración del Estado, donde los servicios públicos son inexistentes o escasos, por ejemplo, donde el acceso a salud es 
Clientelismo personalizado en Colombia: una aproximación histórico-institucional... Luis A. González Tule • Carlos Enrique Guzmán Mendoza • Ángel Tuirán Sarmiento

limitado, los líderes son la representación paternalista del Estado y, como tales, asisten a la población. Atención médica o suministro de medicinas; prioridad en las listas de beneficiarios de programas sociales; disminución del tiempo de espera para realizar un trámite administrativo; asignación de puestos de trabajo; otorgamiento de materiales para construcción; entre otros, son tan sólo algunos de los favores o servicios que proporcionan los mediadores. En respuesta, el cliente asiste a mítines políticos, marcha en manifestaciones, atrae a familiares y amigos y, lo más importante, atrae votos y vota por el candidato que el líder ha ordenado.

En lo más alto de la red de intermediarios, dentro del primer anillo, se encuentran los capitanes, quienes están al frente de cada localidad en la que se divide el municipio ${ }^{14}$. Los capitanes son actores fundamentales dentro del engranaje político-clientelar, pues son los encargados de relacionarse con los coordinadores y líderes, así como de recibir del patrón los recursos que serán distribuidos a los electores. Para atender las demandas de la clientela, los capitanes cuentan con recursos económicos y políticos que provee el patrón. Por ejemplo, a través de la modalidad de las Órdenes de Prestación de Servicios (OPS), asignan puestos de trabajo; también disponen de activos económicos para pagar a sus propios coordinadores y líderes, para organizar eventos, pagar proveedores o trasladar personal a mítines políticos y a las urnas electorales. Cada capitán tiene bajo su organización entre 5 y 10 coordinadores.

En el segundo anillo de intermediarios se encuentran los coordinadores. La función de éstos es vincular a los capitanes con los líderes, transmitiendo las demandas de los últimos a los primeros. Esta figura se activa cuando la cantidad de ciudadanos y de líderes a ordenar es mayor a la capacidad organizativa de la red y se conforma por los líderes más destacados que ascienden un peldaño en el escalafón político-clientelar. Así, cuantas más personas hay que atender y organizar, mayor la necesidad de contar con coordinadores dentro de las localidades en que se divide el municipio. De lo contrario, cuando la red es de menor

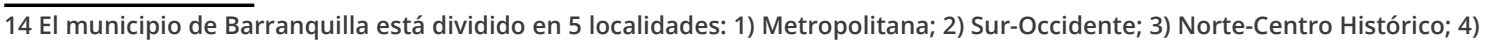
Sur-Oriente; y 5) Riomar. Esta división territorial se mantiene dentro de la organización clientelar. Ver mapa en Anexo 1. 
proporción, los capitanes tienen contacto directo con los líderes sin la mediación del coordinador. Los coordinadores se encargan de canalizar o atender las demandas de entre 10 y 20 líderes.

Los líderes sociales o políticos, quienes se ubican en el tercer anillo, mantienen la relación más cercana con los clientes y pueden dar solución de forma directa a algunas de las necesidades y demandas de los electores o se encargan de transmitirlas a los coordinadores para dar respuesta. En tiempos electorales la función de los líderes se incrementa, pues son los principales responsables de asegurarse que el elector acuda a las urnas el día de las elecciones. "Cada líder debe responder como mínimo con 25 votos", afirmó en entrevista uno de estos intermediarios de la localidad Suroccidente de Barraquilla, y agregó:

De esta manera, se le garantiza un carro o bono de gasolina para mover a los votantes el día de las elecciones. Con lo cual se necesitan aproximadamente 1.000 líderes, 67 coordinadores y 5 capitanes (...) Lo que le permite distribuir los votos y líderes en los 127 puestos de votación en la ciudad. Se necesitan alrededor de 1.500 vehículos para movilizar a toda esa gente, aproximadamente se gasta $\$ 200.000$ por vehículo. Más lo que se le da a cada persona, que puede ser entre $\$ 50.000$ o $\$ 100.000$ pesos. Por lo que, si alguien está interesado en realizar una campaña al Senado o Cámara necesita por lo menos $\$ 300$ millones para movilización el día de elecciones y 2 mil millones más para pagarle a la gente, más comidas, y logística de los coordinadores y líderes. Solo esto el día de las elecciones, en los meses previos se necesitan reuniones, refrigerios y en muchas darle "adelantos" a los votantes para asegurar el voto.

A la par de la escala de intercambio informal descendente, cuando el patrón es el propio candidato, existe una segunda escala vertical de relaciones que fluye de manera ascendente en la que el político se ubica en medio de la red y su función es tanto de patrón, de su propia red, como de mediador frente a otros actores 
Clientelismo personalizado en Colombia: una aproximación histórico-institucional... Luis A. González Tule • Carlos Enrique Guzmán Mendoza • Ángel Tuirán Sarmiento

políticos locales y regionales. Estas posiciones suelen ser ocupadas por concejales cuya carrera política comenzó desde abajo -como líderes políticos- y fue en ascenso hasta adquirir suficiente experiencia y capital político. Es por esta razón que suelen ser los "propietarios" de una estructura clientelar que han construido a lo largo del tiempo, mediante el trabajo comunitario y alianzas con grupos que ostentan el poder político regional.

Figura 2. Red clientelar ascendente en Barranquilla

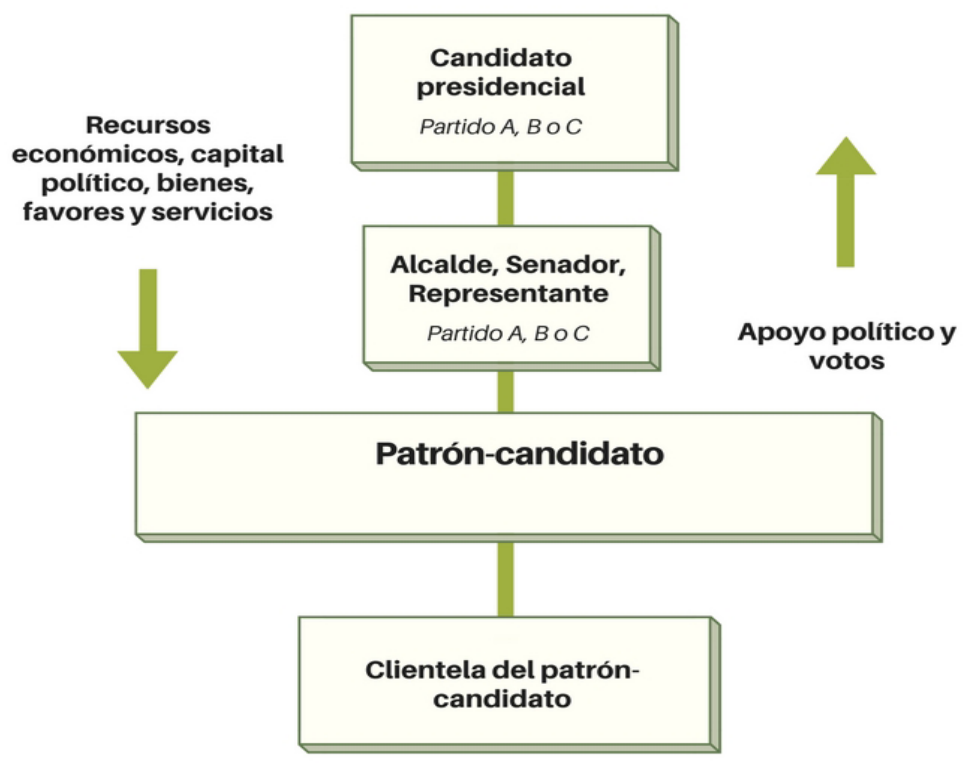

Fuente: Elaborado por los autores.

Un concejal que cuente con capital político amplio y con un gran caudal electoral se convierte en un actor bisagra dentro del escenario político local, pues vincula las clientelas -que están en la base de la pirámide- con la cúpula política nacional y regional ubicadas en la parte más alta de la estructura piramidal -como senadores, congresistas, gobernadores y algunos alcaldes. Por encima de éste es donde se tejen las alianzas con la casa política local. La capacidad de negociación del concejal -o incluso de 
chantaje en los términos de Sartori (1980)- dependerá de su experiencia, de los acuerdos previos y de proyecciones futuras. Pero, principalmente, del tamaño de su red clientelar, medida en número de votos obtenidos en elecciones previas. El patróncandidato proporciona apoyo político y votos al candidato o candidatos que propone la casa política con la que llevó a cabo la negociación. En respuesta, alcaldes, senadores y representantes ofrecen contraprestaciones: recursos económicos, partidas presupuestales, capital político, acceso a servicios y cargos públicos, etc. Esos recursos serán distribuidos a las clientelas electorales a través de los mediadores -capitanes, coordinadores y líderes.

Por último, en la esfera más alta de la red clientelar se encuentran los "barones" (patrones), quienes son las cabezas de las casas -a las que también suele llamárseles "clanes" o "familias" políticas. El barón es el personaje con mayor autoridad política en la región. Por su posición, dispone de recursos de distinta índole: presupuesto público; financiamiento privado -procedente de contratistas del gobierno, por ejemplo; cargos en la burocracia y en la iniciativa privada; entre otros. Estos recursos le garantizan gran influencia a la hora de definir y/o negociar candidatos a alcaldías, gobernaciones, cámaras departamentales y nacionales; gestionar recursos provenientes de la Nación; definir el destino de las partidas presupuestales -por ejemplo, a través de los cupos indicativos, como se verá más adelante; apoyar a líderes políticos y sociales que trabajan en las comunidades; financiar campañas electorales; forjar acuerdos con políticos a nivel regional y nacional, etc. De manera que los barones son el vínculo entre lo local y lo nacional, lo cual se traduce en espacios para la negociación de prebendas -procedentes del centro- por apoyos electorales expresados en votos.

Las casas políticas están vinculadas por parentesco. Luego de los familiares directos -cónyuges, hermanos, hijos, primos, sobrinos-, vendrían los miembros de confianza del clan, quienes son políticos que crecen bajo el cobijo de los barones. Por fuera del clan pero como parte de un grupo político se encuentran los 
Clientelismo personalizado en Colombia: una aproximación histórico-institucional... Luis A. González Tule • Carlos Enrique Guzmán Mendoza • Ángel Tuirán Sarmiento

"aliados", que son líderes y miembros de otros partidos locales o regionales y empresarios e industriales importantes con los que realizan alianzas estratégicas. Si bien las alianzas suelen ser estables y mantenerse por un tiempo, son dependientes de la coyuntura política y de los acuerdos pactados. Las uniones maritales entre miembros de distintos grupos son una vía de acceso al clan familiar. Como si de un régimen monárquico hereditario se tratara, las cabezas de familia buscan transferir su capital político a las siguientes generaciones ${ }^{15}$. Por ello no es extraño que un hijo "herede" la curul del padre cuando éste decide retirarse y no volver a ocupar un cargo de elección popular. La transferencia no es de la curul o del puesto ejecutivo como tal, pues hay que acceder a ellos por la vía electoral, sino del caudal de votos. De ahí que los líderes políticos que crecen al amparo de un barón o de una de las casas tradicionales no lleguen a formar parte del núcleo familiar y rara vez desempeñan un papel protagónico en la política nacional por fuera de estos grupos.

Con el esquema clientelar antes descrito, los partidos han dejado de ser organizaciones encargadas de ofrecer una propuesta política a través de un programa articulado y de seleccionar a los candidatos que competirán en elecciones para convertirse en instrumentos electorales de las casas políticas. Asimismo, la capacidad del ciudadano de utilizar el voto como ejercicio de control sobre los políticos se ha debilitado, pues el elector que recibe los apoyos particulares y condicionados tiende a emitir su voto a partir de los favores o ganancias recibidas y no con base en la evaluación de la gestión del político al frente del gobierno (GONZÁLEZ, 2019b).

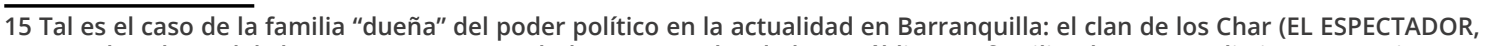
2018). A la cabeza del clan se encuentra Fuad Char, exsenador de la República. La familia Char posee distintos negocios con presencia a nivel local y nacional que van de almacenes y droguerías hasta alimentos, empaques, bienes raíces, publicidad, medios de comunicación y banca (SEMANA, 2019). Fuad Char ingresó al Senado en 1991 y desde la década de 1990 ha influido en la elección de alcaldes y gobernadores, tanto en la política local -del municipio de Barranquilla y del departamento del Atlántico-como regional -de distintos departamentos de la costa Caribe. En 2010 cumplió su último periodo, al cual accedió con 73.000 votos. En 2014 impulsó a su hijo Arturo para el Senado (quien “heredó" la curul), ingresando con 108.000 votos (LA SILLA VACÍA, 2014). Otro de los hijos de Fuad Char, Alejandro, es considerado como el segundo miembro más importante de la casa. Éste ha sido alcalde de Barranquilla en 2 ocasiones (2008-2011 y 2016-2019). Para el 2018, el clan Char contaba con 8 senadores, 5 congresistas, 5 alcaldías y 2 gobernaciones (SEMANA, 2019).
} 


\section{Entendiendo el clientelismo personalizado en Barranquilla}

Este último apartado tiene por objetivo abordar, desde una perspectiva histórico-institucional, los elementos de cambio que influyeron en la forma que adoptó el clientelismo en el municipio de Barranquilla. Para esto, es imperativo analizar el periodo del Frente Nacional (1958-1974) y las reformas de descentralización político-electoral y administrativo-financiera llevadas a cabo en la década de 1980. La importancia del primero se funda en que fue uno de los acontecimientos políticos más importantes en Colombia durante el siglo XX, ya que supuso, entre otros aspectos, poner fin al sectarismo de la lucha entre Liberales y Conservadores de la década anterior, pero que padecía el país desde el siglo XIX (DÁVILA, 1999; LEAL y DÁVILA, 2010). Previo a la creación del Frente Nacional, los líderes locales, también conocidos como gamonales, se articulaban con las "jefaturas naturales"16, adhiriéndose a la ideología de uno de los dos partidos nacionales (LEAL y DÁVILA, 2010). En tanto que las reformas institucionales ampliaron las atribuciones de las administraciones locales, estimulando con ello la fragmentación regional y la concentración de poder de los jefes locales.

El Frente Nacional, formalizado mediante reforma constitucional en 1957, estuvo encaminado a: 1) la reconciliación y pacificación de la alterada vida política, luego de un siglo de luchas y guerras civiles (DÍAZ, 1986; HARTLYN, 1993; LEAL y DÁVILA, 2010); y 2) la institucionalización del monopolio legal del poder político, a través de la alternancia de los dos partidos tradicionales, el Liberal y el Conservador (COSTA, 1971; GUZMÁN, 2005). La rotación acordada garantizó a cada uno de los partidos el acceso al Poder Ejecutivo. Como compensación por el apoyo

\footnotetext{
16 Los "jefes naturales fueron los representantes de los grupos dominantes, en una época en que la pasividad o la actitud servil de las mayorías les daban la apariencia de ser los representantes de todo el pueblo. La ideología de su condición natural de jefes... su carácter obvio e indiscutible, los convertía en supremas autoridades de la dirección pública de la sociedad" (LEAL y DÁVILA, 2010, p. 56).
} 
Clientelismo personalizado en Colombia: una aproximación histórico-institucional... Luis A. González Tule • Carlos Enrique Guzmán Mendoza • Ángel Tuirán Sarmiento

recibido, el partido en el poder entregaba a cambio parte de la burocracia estatal17.

A la par del potencial articulador que tuvo el Frente Nacional sobre las antiguas fuerzas en conflicto, el acuerdo consociativo generó efectos sobre otros elementos del sistema político. La continua alternancia cada cuatro años desdibujó la línea identitaria y diferenciadora de los partidos, propiciando la paulatina desideologización del electorado. Al no existir competencia entre partidos, "ésta se desplazó a su interior" por la búsqueda de puestos de poder (DÁVILA, 1999, p. 66). El debilitamiento ideológico y la pérdida de control de la cúpula partidista pronto acentuaron los conflictos y la competencia interna -anteriormente limitados por la férrea disciplina de las jefaturas naturales (LEAL y DÁVILA, 2010). La dispersión del poder nacional y la necesidad de obtener apoyo de sectores de la población desideologizados llevaron a los partidos a instaurar un sistema político clientelar (DÁVILA, 1999).

Es durante esta etapa que el clientelismo adquirió su forma moderna (DÁVILA, 1999; GUERRERO, 2014), cuando las élites locales y regionales ${ }^{18}$, fortalecidas por la pérdida de poder de las élites tradicionales y agrupadas por casas políticas, pudieron proyectarse hacia el plano nacional (LEAL y DÁVILA, 2010). Senadores y congresistas se convirtieron en voceros y defensores de los intereses de casas políticas regionales y en poseedores de masas de apoyo electoral. La importancia de los políticos departamentales comenzó a medirse a través de la cantidad de votos que lograran movilizar en favor de una clase política nacional fragmentada.

Para llegar al escenario previo, varios factores intervinieron en la nueva correlación de fuerzas. Por un lado se encuentra la implementación del modelo de Industrialización por Sustitución de Importaciones (ISI), desde mediados del siglo XX. El cambio de una producción agrícola a una industrial trajo consigo una mayor urbanización, alteró las relaciones económicas, dinamizó

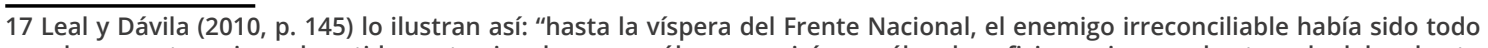
aquel que perteneciera al partido contrario; ahora, no sólo se convivía con él en las oficinas, sino que hasta se le daba el voto para el cargo más codiciado: la [P]residencia de la República".

18 La región se conforma por varios departamentos, mientras que lo local hace referencia al municipio, a un conjunto de municipios contiguos o al departamento. 
Clientelismo personalizado en Colombia: una aproximación histórico-institucional... Luis A. González Tule • Carlos Enrique Guzmán Mendoza • Ángel Tuirán Sarmiento

las clases sociales y aceleró la expansión de las instituciones del Estado. Así, el Estado se vio en la necesidad de mejorar los canales de comunicación con los ciudadanos, a través de agencias gubernamentales para cumplir sus fines en materia de seguridad social, salud, educación, electricidad, entre otros (DÍAZ, 1986). Con este proceso, el papel del Estado se amplió como principal proveedor de servicios y bienes públicos (GUERRERO, 2014), todos ellos dispuestos a ser condicionados a cambio de apoyo político electoral.

Otro aspecto importante atener en cuenta para explicar laforma que adoptan las relaciones del gobierno central con las regiones y con la población fue el proceso de (des)centralización política, administrativa y fiscal. El primer cambio de gran calado ocurrió durante la presidencia de Carlos Lleras Restrepo (1966-1970), con la reforma constitucional de $1968^{19}$. Entre otras modificaciones, esta reforma facultó al Poder Ejecutivo para presentar los proyectos de planes y programas de desarrollo económico y social y los de obras públicas. Dicho poder se encontraba en manos del Congreso (HENAO, 1971). Pese a estos cambios en favor de la centralización y estatalización del Ejecutivo nacional, el Poder Legislativo consiguió algunas contraprestaciones. Tal es el caso de los auxilios regionales -también conocidos como auxilios parlamentarios-, mediante los cuales los legisladores asignaban transferencias del Estado hacia las regiones, y de la creación de institutos descentralizados, con los que se aumentó el tamaño de la burocracia estatal en las regiones, lo que supuso disponer de más cargos en la administración pública (OCAMPO, 2014). Como bien documentó Ocampo (2014, p. 188) para el caso del departamento de Córdoba, "la irrigación de recursos del centro a las regiones fue en las décadas de los setenta y ochenta el carburante del poder de los jefes políticos regionales".

Junto a los acontecimientos hasta ahora descritos, la conformación demográfica en las ciudades sufrió alteraciones considerables debido a la migración de las zonas rurales a los centros urbanos. Esto impactó en la vida política y social de las

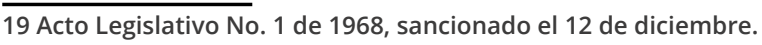


ciudades intermedias. En lo que respecta a Barranquilla, la migración de cientos de campesinos y la llegada de inmigrantes provenientes de otros países fueron un fenómeno que transformó la ciudad por completo (BELL y VILLALÓN, 2000). Muchos de los nuevos habitantes comenzaron a invadir predios y asentarse de forma irregular, creando nuevas urbanizaciones carentes de servicios públicos. Las carencias fueron capitalizadas por líderes populares y concejales, quienes "propiciaban las invasiones, o con fáciles acuerdos municipales declaraban de 'utilidad pública' el suelo urbano invadido” (BELL y VILLALÓN, 2000, p. 258).

Inicia una nueva relación personalizada de intercambio de favores, bienes y servicios por apoyo político desde la base de la pirámide clientelar, la cual servirá, a su vez, como recurso de los líderes políticos barriales para obtener beneficios provenientes de las jefaturas locales. De esta manera, el clientelismo logró convertirse en instrumento clave del sistema político en la medida que se hizo funcional para los fines de la clase política nacional, regional y local: sumar votos y adherir lealtades a cambio de prestaciones y recursos.

Entrada la década de 1980, se llevaron a cabo reformas descentralizadoras a partir de las cuales fueron configurándose nuevas relaciones entre la estructura de poder territorial y el Estado central (GUTIÉRREZ, 2010). Las primeras reformas en esa dirección fueron emprendidas por el presidente Belisario Betancur (19821986), en 1986. Por un lado, se introdujo la elección popular de alcaldes municipales -quienes previamente eran designados por el gobernador departamental- $y$, por otro, se entregó a los municipios la administración de las políticas de salud, vivienda, educación y servicios públicos. La primera medida buscaba "debilitar las estructuras partidistas regionales cuyos dirigentes participaban, con los gobernadores, en la designación de los alcaldes" (OCAMPO, 2014, p. 190). Sin embargo, la competencia electoral por las alcaldías terminó por fortalecer el clientelismo de base, pues las casas políticas locales ahora negociaban directamente con los líderes barriales.

El cambio institucional de mayor trascendencia arribó con la nueva Constitución de 1991, aprobada durante la gestión del 
Clientelismo personalizado en Colombia: una aproximación histórico-institucional... Luis A. González Tule • Carlos Enrique Guzmán Mendoza • Ángel Tuirán Sarmiento

presidente César Gaviria (1990-1994). Por su efecto sobre el tema de análisis del presente estudio, importa rescatar algunos de los cambios político-electorales y fiscales de la nueva Carta Magna. En relación con los sistemas electoral y partidista destacan las siguientes modificaciones: 1) establecimiento de la elección popular de gobernadores, antes designados por el Presidente de la República; 2) separación de las elecciones locales y regionales de las nacionales; 3 ) introducción de nuevas fórmulas para el registro de partidos políticos; y 4) institucionalización del financiamiento público para los partidos ${ }^{20}$.

De igual importancia resultaron las disposiciones fiscales contenidas en la Constitución. Destacan: 1) mayor autonomía local para recaudar impuestos; 2 ) reasignación de los entes territoriales de funciones que antes pertenecían al gobierno nacional; y 3) aumento en las transferencias para la inversión en distintos sectores (EL PAÍS, 2016). Junto a las nuevas directrices fiscales, la Constitución eliminó los auxilios regionales. Sin embargo, poco después surgió una nueva modalidad de acceso a partidas presupuestales especiales por parte de los legisladores. Se trata de los "Fondos de inversión con gestión congresional", después llamados "Cupos indicativos" (OCAMPO, 2014). A través de los cupos indicativos, los legisladores reciben una partida para cubrir necesidades sociales de sus regiones. Uno de los puntos más controvertidos de los cupos es que los legisladores deciden a qué alcalde designan los recursos e incluso, por disposición de la Corte Constitucional en 2001, pueden sugerir a qué obra pública se destinan (PORTAFOLIO, 2018).

Así, el modelo de descentralización implementado con la Constitución de 1991 permitió a las entidades territoriales obtener mayor margen de autonomía para la gestión de sus intereses, gobernarse por autoridades propias, ejercer competencias exclusivas, administrar los recursos y establecer los tributos para el cumplimiento de estas competencias. De igual manera,

\footnotetext{
20 Otros cambios de igual importancia en términos político-electorales implicaron lo siguiente: 1) introducción de la segunda vuelta presidencial; 2) creación de una circunscripción nacional para elegir senadores y de circunscripciones especiales para minorías; 3) establecimiento de un régimen de inhabilidades e incompatibilidades para los congresistas, miembros de asambleas, concejos y juntas administradoras; y 4) posibilidad de presentar candidatos por fuera de los partidos políticos.
} 
Clientelismo personalizado en Colombia: una aproximación histórico-institucional... Luis A. González Tule • Carlos Enrique Guzmán Mendoza • Ángel Tuirán Sarmiento

sirvió a las administraciones departamentales y municipales para participar en las rentas nacionales para llevar a cabo inversiones en los sectores de salud, educación y saneamiento básico.

La descentralización permitió que se consolidaran estructuras clientelares al servicio de poderes locales o casas políticas con amplio dominio territorial. Tales estructuras normalmente se configuran en el marco de lo que autores como Dávila (1999) y García y Revelo (2010) Ilaman “clientelismo de mercado”. Esta forma de clientelismo tiene a los políticos y contratistas de obra pública como patrones, que se valen, primero, de la descentralización fiscal para capturar los recursos transferidos a través de los cupos indicativos o del Sistema General de Participaciones ${ }^{21}$, y segundo, de la elección popular de mandatarios locales para controlar la burocracia y contratación en las regiones. De modo que las antiguas relaciones del clientelismo se adaptaron a los cambios institucionales (DÁVILA y DELGADO, 2002). La adaptación a las reformas por parte de las casas políticas en Barranquilla, como se vio en el apartado anterior, no fue la excepción, confirmando el carácter dinámico-personalista que adopta el clientelismo al interior de grupos políticos desideologizados (GARCÍA y GODOY, 2009).

\section{Reflexiones finales}

En este artículo nos propusimos mostrar cómo opera el clientelismo y proponer explicaciones para entender la lógica del intercambio. Argumentamos que el clientelismo en Barranquilla es de naturaleza personalizada y no partidista como resultado de los arreglos políticos y los cambios institucionales que han tenido lugar en Colombia desde mediados del siglo XX. A través de un análisis histórico-institucional, hemos evidenciado que el entendimiento del clientelismo en el municipio no puede ser abordado sin considerar

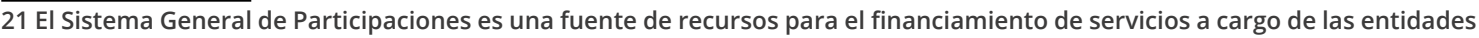
territoriales (departamentos, municipios y distritos principalmente de cuarta, quinta y sexta categoría), en educación, salud, agua potable y saneamiento básico, al igual que en otros sectores denominados de propósito general (DEPARTAMENTO NACIONAL DE PLANEACIÓN, 2019).
} 
el contexto actual ni los procesos políticos y sociales por los que ha atravesado el país. El acuerdo entre Liberales y Conservadores terminó por fortalecer los cacicazgos regionales, de modo que la pugna por el poder departamental y municipal ya no se expresó a través del binomio liberalismo-conservatismo, carente de contenido, sino a través de familias y clanes, personalizando así las relaciones políticas y la administración de las entidades públicas. Mientras que el cambio que surgió de la mano de las reformas político-administrativas impulsadas a mediados de la década de 1980 supuso un cuantioso incremento de los recursos estatales para gestionar en la política local, por tanto, más dinero y de más fácil acceso para financiar las redes clientelares y pagar favores y servicios.

Además de mostrar el funcionamiento de una red clientelar en el municipio y de encontrar explicaciones que ayuden a entender el fenómeno, buscamos contribuir al debate dentro de la Ciencia Política indagando en lasimplicaciones del clientelismo en el régimen democrático. Sobre este particular, cabe concluir, por un lado, que el clientelismo -visto desde una perspectiva procedimental- altera las normas del juego democrático. Concretamente, la capacidad del ciudadano para exigir cuentas -la cual se ve limitada al condicionar su voto al intercambio de prebendas- y el derecho a competir por cargos en condiciones justas y equitativas -en cuyo caso se ven afectados los candidatos que deseen atraer el voto ideológicoprogramático por fuera de las estructuras clientelares.

Por otro lado, en términos sustantivos, los hallazgos nos permiten afirmar que la práctica es perjudicial para la sociedad en su conjunto desde el momento en que se convirtió en un instrumento de los clanes políticos subnacionales para afianzarse en el poder. La diferencia que separa a esos clanes, quienes poseen recursos económicos, simbólicos y políticos, del elector, quien recibe una ayuda que no lo sacará de su condición desfavorable, es parte de un círculo vicioso en el que las élites se perpetúan en los cargos de representación y gobierno, desde los cuales disponen de recursos de Estado, manejan licitaciones de obra pública y controlan el 
acceso a cargos públicos. El clientelismo -sea personalizado o partidario- en sistemas poco o nada competitivos, caracterizados por la falta de alternancia política y un pluralismo limitado, como el caso de Barranquilla, es una forma de dominación que mantiene las asimetrías entre gobernantes y gobernados en sociedades ya de por sí desiguales.

\section{Referencias}

AUYERO, Javier (comp.). ¿Favores por votos? Estudios sobre clientelismo político contemporáneo. Buenos Aires: Losada, 1997.

AUYERO, Javier. La política de los pobres. Las prácticas clientelistas del peronismo. Buenos Aires: Manantial, 2012.

BELL, Carlos; VILLALÓN, Jorge. El periodo del Frente Nacional y la crisis de los años sesenta (1957-58-1974-75). Bogotá: Ed. Universidad del Norte, 2000.

BRIQUET, Jean-Louis. Clientelism. Disponible en: https://www. britannica.com/topic/clientelism. Acceso en: 18 mar. 2020.

COSTA, Luis. Voto y cambio social. El caso colombiano en el contexto latinoamericano. Bogotá: Tercer Mundo, 1971.

DÁVILA, Andrés. Clientelismo, intermediación y representación política en Colombia: ¿Qué ha pasado en los noventa? Estudios Políticos, n. 15, p. 61-78, 1999.

DÁVILA, Andrés; DELGADO, Natalia. La metamorfosis del sistema político colombiano: ¿Clientelismo de mercado o nueva forma de intermediación? In: GUTIÉRREZ, Francisco (comp.). Degradación o cambio: evolución del sistema político colombiano. Bogotá: Instituto de Estudios Políticos y Relaciones Internacionales/ Norma, 2002. p. 319-352.

DEPARTAMENTO NACIONAL DE PLANEACIÓN. Sistema General de Participaciones - SGP. Disponible en: https://www.dnp.gov. 
co/programas/inversiones-y-finanzas-publicas/Paginas/SistemaGeneral-de-Participaciones---SGP.aspx. Acceso en: 11 nov. 2019. DÍAZ, Eduardo. El clientelismo en Colombia. Un estudio exploratorio. Bogotá: El Áncora, 1986.

EL ESPECTADOR. Estas son las familias dueñas del poder político en las regiones de Colombia. 10 mar. 2018. Disponible en: https://www.elespectador.com/elecciones-2018/noticias/politica/estas-son-las-familias-duenas-del-poder-politico-en-las-regiones-de-colombia-articulo-743276. Acceso en: 9 nov. 2019.

\section{EL PAÍS. Cinco grandes cambios que trajo la Constitución de} 1991. 3 jul. 2016. Disponible en: https://www.elpais.com.co/colombia/cinco-grandes-cambios-que-trajo-la-constitucion-de-1991. html. Acceso en: 9 nov. 2019.

FERRO, Jesús; LLANOS, Rossana. Memorias de El Prado: arquitectura y urbanismo. 1920-1960. Barranquilla: Ed. Universidad del Norte, 2016.

GARCÍA, Jairo; GODOY, Horacio. Partidos, movimientos y facciones en las elecciones populares de alcaldes en Barranquilla (Colombia), 1988-2007. Investigación y Desarrollo, n. 17, v. 1, p 62-83, 2009.

GARCÍA, Mauricio; REVELO, Javier. Estado alterado. Clientelismo, mafias y debilidad institucional en Colombia. Bogotá: DeJusticia, 2010.

GONÇALVES, João. O clientelismo partidario durante a I República: o caso do Partido Reconstituinte (1920-1923). Análise Social, n. 32, v. 140, p. 31-74, 1997.

GONZÁLEZ, Luis. Introducción: claves para entender el clientelismo político. In: GONZÁLEZ, Luis (ed.). Clientelismo, patronazgo y corrupción en Colombia y México. Bogotá: Ed. Universidad del Norte, 2019a. p. 1-21. 
GONZÁLEZ, Luis. Clientelismo y democracia: descifrando una (difícil) relación. In: GONZÁLEZ, Luis (Ed.). Clientelismo, patronazgo y corrupción en Colombia y México. Bogotá: Ed. Universidad del Norte, 2019b. p. 283-297.

GONZÁLEZ, Luis; GUZMÁN, Carlos; TUIRÁN, Ángel. Clientelismo de medicación en Barranquilla. In: GONZÁLEZ, Luis (ed.).

Clientelismo, patronazgo y corrupción en Colombia y México. Bogotá: Ed. Universidad del Norte, 2019. p. 54-75.

GUERRERO, Laura. Clientelismo político, ¿Desviación de la política o forma de representación? Estado del arte sobre las aproximaciones al clientelismo en Colombia 1973-2011. Bogotá: Ed. Universidad del Rosario, 2014.

GUTIÉRREZ, Francisco. Instituciones y territorio. La descentralización en Colombia, en 25 años de la descentralización en Colombia. Bogotá: Konrad Adenauer Stifttung, 2010.

GUZMÁN, Carlos. Política, descentralización y subsistemas regionales de partidos, 1988-2000. Una explicación teórica y un análisis empírico. Ibagué: Universidad de Ibagué, 2005.

HAGENE, Turid. Political clientelism in Mexico: bridging the gap between citizens and the State. Latin American Politics and Society, v. 57, n. 1, p. 139-162, 2015.

HAGOPIAN, Frances. The compromised consolidation: the political class in the Brazilian transition. In: MAINWARING, Scott; O'DONNELL, Guillermo; VALENZUELA, Samuel (comp.). Issues in democratic consolidation. The new South American democracies in comparative perspective. Notre Dame: University of Notre Dame, 1992. p. 243-293.

HARTLYN, Jonathan. La política del régimen de coalición. La experiencia del Frente Nacional en Colombia. Bogotá: Tercer Mundo, 1993. 
HECKATHORN, Douglas. Respondent-driven sampling: a new approach to the study of hidden populations. Social Problems, n. 44, v. 2, p. 174-199, 1997.

HENAO, Javier. La reforma constitucional de 1968. Estudios de Derecho, v. 30, n. 80, p. 271-287, 1971.

HILGERS, Tina. Clientelism in everyday in Latin American politics. New York: Palgrave Macmillan, 2012.

IPPOLITO-O'DONNELL, Gabriela. The subversion of public space: clientelism and the quality of democracy. San Martín: Universidad Nacional de San Martín, 2007. (Serie Documento de Trabajo No. 6).

KITSCHELT, Herbert. Linkages between citizens and politicians in democratic polities. Comparative Political Studies, n. 33, v. 6, p. 845-879, 2000.

KITSCHELT, Herbert; WILKINSON, Steven (eds.). Patrons, clients, and policies. Patterns of democratic accountability and political competition. Cambridge: Cambridge University Press, 2007.

KOPECKÝ, Con Petr. El patronazgo partidario como recurso organizativo. In: CASAL, Fernando; SCHERLIS, Gerardo (comp.).

Partidos, sistema de partidos y democracia. La obra esencial de Peter Mair. Buenos Aires: Eudeba, 2015. p. 109-146.

LA SILLA VACÍA. Los súper poderosos de Barranquilla. 1 abr. 2014. Disponible en: https://lasillavacia.com/historia/los-super-poderosos-de-barranquilla-46997. Acceso en: 10 nov. 2019.

LEAL, Francisco; DÁVILA, Andrés. Clientelismo: el sistema político y su expresión regional. Bogotá: Universidad de los Andes, 2010.

MAINWARING, Scott; TORCAL, Mariano. La institucionalización de los sistemas de partidos y la teoría del sistema partidista después de la tercera ola democratizadora. América Latina Hoy, n. 41, p. 141-173, 2005. 
MISIÓN DE OBSERVACIÓN ELECTORAL - MOE. Mapas y factores de riesgo electoral. Elecciones nacionales Colombia 2018. Bogotá: Arte Litográfico, 2018.

MISIÓN DE OBSERVACIÓN ELECTORAL - MOE. Mapas y factores de riesgo electoral. Elecciones de autoridades locales Colombia 2019 (Resumen Ejecutivo). Bogotá: MOE, 2019.

OCAMPO, Gloria. Poderes regionales, clientelismo y Estado. Etnografía del poder y la política en Córdoba, Colombia. Bogotá: Siglo del Hombre, 2014.

PIATTONI, Simona. Clientelism in historical and comparative perspective. In: PIATTONI, Simona (ed.). Clientelism, interest, and democratic representation. The European experience in historical and comparative perspective. Cambridge: Cambridge University Press, 2001. p. 1-30.

PORTAFOLIO. Cupos indicativos. El $67 \%$ de los municipios de Colombia deben cerrar brechas en cuanto a cobertura en educación. 17 oct. 2018. Disponible en: https://www.portafolio. co/opinion/otros-columnistas-1/cupos-indicativos-columnista-522400. Acceso en: 11 nov. 2019.

RONIGER, Luis. Hierarchy and trust in modern Mexico and Brazil. New York: Praeger, 1990.

SARTORI, Giovanni. Partidos y sistema de partidos. Madrid: Alianza, 1980.

SCOTT, James. Corruption, machine politics and political change. American Political Science Review, v. 63, n. 4, p. 1142-1158, 1969.

SEMANA. ¿Quiénes son los Char? 4 jul. 2019. Disponible en: https://www.semana.com/nacion/articulo/quienes-son-la-familiachar/608494/. Acceso en: 7 nov. 2019. 
SHEFTER, Martin. Political parties and the State. The American historical experience. Princeton, NJ: Princeton University Press, 1994.

STOKES, Susan. Perverse accountability: a formal model of machine politics with evidence from Argentina. American Political Science Review, v. 99, n. 3, p. 315-325, 2005.

TUIRÁN, Ángel; VILLALBA, Luis. Elecciones y clientelismo político: una aproximación a la caracterización de los intermediarios electorales en el distrito de Barranquilla. In: TREJOS, Luis; GUZMÁN, Carlos (ed.). Barranquilla, política economía y sociedad. Barranquilla: Ed. Universidad del Norte, 2018. p. 59-84. VOMMARO, Gabriel; COMBES, Hélène. El clientelismo político. Desde 1950 hasta nuestros días. Buenos Aires: Siglo XXI. 2016. WARNER, Carolyn. Mass parties and clientelism in France and Italy. In: PIATTONI, Simona (ed.). Clientelism, interest, and democratic representation. The European experience in historical and comparative perspective. Cambridge: Cambridge University Press, 2001. p. 122-151. 